\title{
Reflexões sobre a dinâmica psíquica de trabalhadores afastados do trabalho ${ }^{\star}$
}

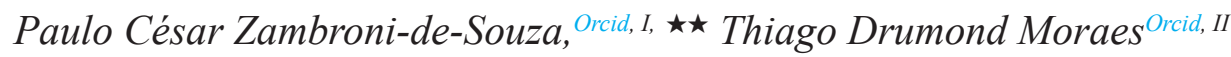 \\ ${ }^{I}$ Universidade Federal da Paraiba, João Pessoa, PB, Brasil \\ ${ }^{I I}$ Universidade Federal do Espírito Santo, Vitória, ES, Brasil
}

\section{Resumo}

\begin{abstract}
A partir da Psicodinâmica do Trabalho, reflete-se sobre a dinâmica psíquica de trabalhadores afastados do emprego por doença surgida elou agravada no trabalho. Entre os conceitos desta abordagem que contribuem para a compreensão do fenômeno destacam-se: trabalho e sua relação com a subjetividade, sofrimento, coletivo, e reflexões sobre relações entre rupturas involuntárias da atividade profissional e adoecimento. Aponta-se a urgência da investigação: da relação de modelos gestionários com as formas de adoecimento e afastamento do emprego; da problemática da reabilitação profissional; e das possiblidades de utilização da metodologia desta abordagem para grupos de profissionais oriundos de distintos meios de trabalho.
\end{abstract}

Palavras-chave: trabalho; adoecimento; dinâmica psíquica; psicodinâmica do trabalho.

\section{Reflections on the psychic dynamics of workers in leave of absence from work}

\begin{abstract}
From the Psychodynamics of Work, it is analyzed the psychic dynamics of workers away from work due to illness arising and/or aggravated at work. Among the concepts of this approach contributing to the understanding of the phenomenon stand out: work and its relation with subjectivity, suffering, collective, and reflections on the relations between involuntary ruptures of professional activity and illness. It urges to investigate: the relation of management models with forms of sickness and absence from work; the problem of professional rehabilitation; and the possibilities of using the methodology of this approach for groups of professionals from different working environments.
\end{abstract}

Keywords: work; illness; psychic dynamics; psychodynamics of work.

\section{Introdução}

Considerando a grande complexidade que atravessa os mundos do trabalho no Brasil, entendemos ser necessário que diversos vocábulos frequentemente utilizados (nem sempre com rigor conceitual) tenham aqui uma definição suficientemente clara, de modo que uma análise psicológica do trabalho e as questões aqui tratadas possam avançar fora de um terreno movediço e mais ideologizado.

No campo das ciências econômicas e jurídico-políticas circulam noções sobre as quais não há consenso. Como exemplo, há intensa polêmica em torno do que seria mercado, (des)emprego, (in)formalidade, cuja conceituação extrapola a Psicologia. Para nossa análise avançar, registramos a diferenciação entre trabalho e emprego, considerando que este último se define por uma relação jurídica de natureza contratual, regulamentando o vínculo obrigacional de subordinação do empregado ao empregador, contemplando também as obrigações deste frente às imposições da legislação sobre o trabalho no Brasil, que tem como grande marco a promulgação da Consolidação das Leis do Trabalho em 1943 (BRASIL, 1943), diversas vezes modificada desde então e cuja recente modificação defere duros golpes nos direitos dos trabalhadores com as alterações estabelecidas pela (BRASIL, 2017a). Assim, quando no artigo usarmos o vocábulo "emprego", estaremos considerando exclusivamente o trabalho daqueles que têm este enquadramento jurídico-político.

^O presente trabalho foi realizado com o apoio do CNPq, Conselho Nacional de Desenvolvimento Científico e Tecnológico - Brasil.

$\star \star$ Endereço para correspondência: Universidade Federal da Paraíba, Campus I Centro de Ciências Humanas, Letras e Artes - Departamento de Psicologia. Conjunto Humanístico, Bloco IV - Cidade Universitária - João Pessoa, PB - Brasil. CEP: 58059-900.E-mail: paulozamsouza@yahoo.com.br, tdrumond@gmail.com
Não obstante, sabemos que os mundos do trabalho no Brasil apresentam um complexo e cinzento cenário, com a presença do que alguns denominam economia "informal", assim como um mercado "informal". Mais grosseira é a denominação "emprego informal", que recusamos, como também a de "subemprego", dado que ambas mais escondem que revelam a dura realidade vivida pelos humanos em tais situações.

Toda formação social, em diferentes conjunturas, apresenta uma polimorfia em suas relações de trabalho. E o que de mais importante consideramos para a análise a ser apresentada é o registro de que a grande maioria dos que trabalham fora do salariato (regime salário-emprego) está com suas condições de sobrevivência ainda mais profundamente fragilizadas do que aquele que está no sistema. Seja ao se encontrar excluído de seu trabalho habitual, seja ao adoecer.

Tal temática já estava presente na obra de Dejours (1992) desde seu início, como encontramos em $A$ loucura do trabalho: estudo de psicopatologia do trabalho, publicado no Brasil em 1987. Neste livro, o autor se interessa pela situação de trabalho, vida e saúde do subproletariado, pessoas que trabalham frequentemente sem vínculo empregatício.

Como o presente artigo insere-se em um dossiê de caráter histórico, convém ainda pontuar que este livro, fundamental para a difusão da obra de Dejours em vários países, tem seu título original como "Travail: usure mentale", lançado na França em 1980, cuja tradução literal para o português seria "Trabalho: desgaste mental". Embora não seja público o processo que levou os editores a proporem o título que foi atribuído no Brasil, a alusão 
ao tema da loucura, junto com o excelente conteúdo do próprio livro, possivelmente colaborou para seu enorme sucesso entre nós.

O presente artigo trata da dinâmica psíquica de trabalhadores afastados do emprego, buscando compreendê-la a partir da Psicodinâmica do Trabalho. Entende-se que tal questão está presente desde o início da obra Dejouriana, como se apresenta em vários de seus textos iniciais (DEJOURS, 1980,1983), especificamente em sua obra que o apresenta para o grande público (DEJOURS, 1980). Nesta o autor trabalha seus conceitos a partir de dois grupos opostos: os pilotos de caça da Força Aérea francesa, trabalhadores muito qualificados e valorizados socialmente; e o subproletariado, composto por trabalhadores com baixo nível de qualificação e que estão frequentemente à beira da miséria. Particularmente quando discute o caso dos que se afastam por motivo de doença, com grande e frequente risco de serem colocados à margem da sociedade, de entrarem em estado de miserabilidade, de subproletariado.

Para não supormos que esse texto de 1980 de Dejours seja anacrônico, vale observar que em 2015, no Brasil, do total de 1.542.371 trabalhadores com carteira assinada (MODZELESKI, 2016), 196.761 trabalhadores receberam novos auxílios por doença concedidos pelo Instituto Nacional do Seguro Social (BRASIL, 2015), o que representa $12,75 \%$ do total de empregados pelas Consolidações das Leis do Trabalho, sem aí considerar os acidentados. Pode-se considerar, no entanto, que o número de trabalhadores adoecidos seja maior, já que devido à "ideologia da vergonha" (DEJOURS, 2015a), muitos apenas se reconhecem como doentes quando já não conseguem sequer dirigir-se ao trabalho. Além disso, muitas vezes o trabalhador receia que ao não ir trabalhar (seja mesmo por não sentir-se em condições de saúde), possa vir a ser demitido, ser bloqueado na progressão de carreira, perder alguns "benefícios" (como licenças por tempo de serviço) conquistados por sua categoria profissional, enfim por não ser visto pelos colegas como um "traidor", um "desertor" na guerra como muitas vezes é visto o trabalho. Pesquisa de longa duração com trabalhadores de escola da rede pública apresenta os conflitos interpares geradas pelo adoecimento de colegas, inclusive quando só parcialmente afastados pela perícia com o registro administrativo de readaptação (BRITO; ATHAYDE; NEVES, 2003; BRITO et al., 2003). Enfim, na realidade, por diversas razões há subnotificação de adoecimentos e acidentes muito frequentes, quadro que se agrava pelo fato de muitos não saberem a quem procurar, quais seus direitos, etc.

Tal quadro de adoecimento traz inevitavelmente prejuízos não só para as organizações, sejam ou não empresariais, públicas ou privadas, bem como para o Estado, assim como para os trabalhadores. Estes últimos são acometidos por prejuízos de diversas ordens (psíquica, corporal, financeira, nas relações familiar e social) ao adoecer, em especial por alguma enfermidade surgida ou agravada em função de sua relação com o próprio trabalho. As organizações deixam de contar com esses trabalhadores, muitos deles possuidores de experiência, qualificações e competências indispensáveis, além de gerar uma rotatividade não estratégica na concorrência com outras organizações. O Estado precisa custear as despesas de manutenção desses trabalhadores, insuficientes que sejam, através da concessão de auxílios pela previdência social, conforme a lei nº 8.213, de 1991 (BRASIL, 1991). Dados da Organização Internacional do Trabalho (OIT) informam que se "estima que os acidentes de trabalho e as doenças profissionais resultam numa perda anual de $4 \%$ no produto interno bruto (PIB) mundial, ou cerca de 2,8 bilhões de dólares" (INTERNATIONAL LABOR ORGANIZATION, 2013, p. 7).

Ainda que se ressaltem aqui as dimensões deletérias das relações de emprego, há que se considerar que o trabalho é a operação pela qual o humano não só transforma a natureza, como também a si próprio (DEJOURS, 2012a; 2012b; 2012c), em uma processualidade que pode ser afirmativa da potencialidade do viver já que "o trabalho nunca é neutro com relação à saúde e favorece seja a doença, seja a saúde" (DEJOURS, 1992, p. 164). Por isso que muitos trabalhadores experimentam uma situação paradoxal: enfrentam meios de trabalho hostis, organização e/ou condições do trabalho que favorecem a via patogênica do sofrimento e o adoecimento, levando muitas vezes ao afastamento do trabalho, nem sempre reconhecidos pela perícia médica e amparados pela Previdência Social. No entanto, quando se afastam daquele trabalho nocivo, mesmo que passem a receber o "auxílio" do INSS, conforme a lei no 8.213 (BRASIL, 1991), caem em uma situação da qual é muito difícil sair: muitas vezes ficam revivendo aquele sofrimento (PEZÉ, 2008), com temor de nunca mais se recolocar no mercado, empobrecendo suas vidas, trazendo problemas para as dinâmicas social e familiar, além de impedirem a vivência subjetiva da atividade do trabalho que podem conduzir à saúde psíquica (DEJOURS, 2012c). Desta forma, um quadro paradoxal e conflitivo se configura: por um lado, permanecer naquele emprego que se revelou um meio deletério, mesmo após o restabelecimento e a volta da licença médica pode representar a reincidência ou agravamento do problema; por outro lado, sair dele pode trazer uma série de outras formas de sofrimento também patógenas como foi antes assinalado.

De modo geral, os trabalhadores que se encontram nesta lamentável situação podem ter travado o desenvolvimento de suas capacidades subjetivas (cognitivas, afetivas, sociais). Apesar disso, mesmo no caso de pessoas com diagnóstico de transtornos mentais graves, alguns pouquíssimos conseguem se desvencilhar dessa situação (ZAMBRONI-DE-SOUZA, 2006a; ZAMBRONI-DE-SOUZA; ATHAY$\mathrm{DE}, 2006)$, pois assim como a relação entre aqueles que trabalham e a organização do trabalho não é um bloco monolítico (DEJOURS, 2015a), também cada trabalhador em sua vida pode encontrar soluções mesmo nas situações mais adversas, em caso de fracasso sucumbindo cada vez mais à gravidade do transtorno, ao adoecimento.

O trabalho é constitutivo da espécie e estruturante do psiquismo, mas pode tornar-se o contrário. Pode ser ocasião de superar os limites do corpo, condição de sub- 
jetivação no mundo, de formação da engenhosidade. De modo que ser afastado de seu exercício (em função de acidentes ou formas de adoecimento gerados ou agravados no/pelo trabalho) pode gerar vivências complexas. No artigo visamos apresentar uma análise inicial acerca de como se configura a dinâmica psíquica dos trabalhadores após terem sido afastados do seu emprego em decorrência de doença diagnosticada como tendo surgido e/ou agravada no próprio trabalho, a partir da abordagem da Psicodinâmica do Trabalho (DEJOURS, 2012c, 2015b).

A abordagem Psicodinâmica do Trabalho (PDT) tem seu foco nas "pesquisas que vão do sofrimento ao prazer no trabalho, das patologias mentais à realização de si mesmo através do trabalho" (DEJOURS, 2013, p. 10). Ela é herdeira da Psicopatologia do Trabalho (PPT) de origem francesa, que teve seu começo nos acontecimentos da $2^{\mathrm{a}}$ Guerra, sendo que esta denominação foi anunciada pela primeira vez em 1952 por Sivadon, um de seus fundadores, ao lado de Le Guillant (BILLIARD, 2001; DEJOURS; GERNET, 2012; ZAMBRONI-DE-SOUZA; ATHAYDE, 2006; ZAMBRONI-DE-SOUZA et al., 2009). Aquela que foi, até a década de 1980, uma de suas correntes - AOCIP (Associação pela Abertura do Campo da Psicopatologia do Trabalho) - configurou-se em outra abordagem (a PDT), incorporando no seu interior a PPT, tendo em Christophe Dejours seu fundador e principal referência científica.

\section{Algumas relações entre trabalho e processo saúde- doença psíquica}

Segundo a PDT, o trabalho apresenta-se como central para a produção da subjetividade e para a busca da saúde (entendida como um ideal, não um estado). Dejours (1999, p. 42-43) o define como "atividade coordenada desenvolvida por homens e mulheres para enfrentar aquilo que, em uma tarefa utilitária, não pode ser obtido pela execução estrita da organização prescrita". Ou seja: o trabalho é, antes de mais nada, atividade. Dizer isso remete à distinção estabelecida pela ergonomia entre trabalho prescrito e trabalho real (GUÉRIN et al., 2012). O hiato entre ambos, sempre enigmático, quando detectado no curso do trabalhar, é "preenchido" pelos operadores através da sua mobilização subjetiva (interpretando e equacionando a defasagem, descobrindo soluções), algo que não é antecipável. Sem tal mobilização subjetiva nada acontece, já que "o caminho a ser percorrido entre o prescrito e o efetivo deve ser a cada momento inventado ou descoberto pelo sujeito que trabalha" (DEJOURS, 2012a, p. 25).

Embora os afastados do emprego nunca estejam de fato inativos, (suas atividades persistentes seriam importante objeto de investigação), a ausência daquelas atividades que compunham seu emprego certamente os afeta - de algum modo, em alguma medida - em sua vida e formas de luta pela saúde, seus sistemas defensivos. Por outro lado, conforme mostra nossa própria experiência clínica com trabalhadores nesta situação que acompanhamos no Programa de Saúde do Trabalhador da Universidade Federal da Paraíba (CAVALCANTI; ZAMBRONI-DE-SOUZA; UCHÔA-DE-MEDEIROS,
2013), podemos afirmar que, frequentemente, eles muitas vezes assim se encontram exatamente porque já apresentam sintomas como problemas de coluna, de membros superiores, depressão, etc. Um quadro que praticamente inviabiliza ou dificulta a realização de atividades as mais cotidianas, mesmo em suas casas (VIDAL, 2007).

Vale mencionar ainda que a atividade de trabalho é coordenada, ou seja,

[...] a coordenação designa a prescrição dada pela organização do trabalho das relações entre os indivíduos. [...] A divisão social e técnica do trabalho que caracteriza a coordenação se assevera necessária", fazendo com que cada um leve em conta o trabalho que outros realizam antes, durante ou depois da sua atividade, o que pode fornecer "um quadro de referência aos laços de cooperação (DEJOURS, 2012a, p. 25).

Assim, é necessária uma coordenação de inteligências de trabalhadores que possam cooperar entre si visando um objetivo comum, aliando coordenação e cooperação, já que o trabalho não é nunca uma atividade de caráter solipsista, tendo sempre outro envolvido e implicado, de tal forma que "a cooperação supõe um compromisso que é a um só tempo técnico e social. Isso se deve ao fato de que trabalhar não é, em tempo algum, apenas produzir: é também e sempre viver junto" (DEJOURS, 2012a, p. 38).

Desta forma, o trabalho se desdobra sempre em três universos: objetivo, social e subjetivo (DEJOURS; MOLINIER, 2004). As formas contemporâneas de gestão tendem a destruir os laços de cooperação entre os trabalhadores, destruindo os coletivos e deixando cada um sozinho e enfraquecido diante da organização do trabalho (DEJOURS, 2012b, 2015b), favorecendo o aparecimento de doenças, pois os métodos contemporâneos de gestão "instalam no mundo do trabalho o cada um por si, a deslealdade, a desestruturação do convívio, produzindo uma implacável solidão em meio à multidão" (DEJOURS, 2009, p. 50).

Outro aspecto importante na relação trabalho e processo saúde-doença é que essa atividade é desenvolvida por homens e mulheres, o que traz à tona questões ligadas à divisão sexual e social do trabalho, às "relações de sexo/gênero" (HIRATA; KERGOAT, 2007, p. 607), tendo, entre outros efeitos, a desvalorização do lugar da mulher na sociedade, de modo "que as relações sociais de sexo são indissociáveis das relações sociais de trabalho e de que as relações sociais de trabalho são sempre, simultaneamente, relações sociais de sexo" (DEJOURS, 2004b, p. 318).

Dizer que o trabalho é realizado por homens e mulheres lança luz ao que elas realizam, contrapondo o fato de que, apesar de as mulheres terem sempre trabalhado (SCHWEITZER, 2002), via de regra, seu trabalho foi tomado como invisível, desqualificado, ou pelo menos recebeu menos valorização e visibilidade que o realizado por homens. Em muitos meios de trabalho a virilidade é usada como elemento de classificação de trabalhadores e pressão sobre eles, como descrito em artigo de um dos autores, em que a coação viril é utilizada como forma de manter a produtividade, causando grandes prejuízos para a saúde física e mental de trabalhadores com LER/ 
DORT, que acabam por se afastar novamente do trabalho após voltarem de licença médica (SILVA; OLIVEIRA; ZAMBRONI-DE-SOUZA, 2011). Ao mesmo tempo, é em torno da virilidade que se sustentam alguns sistemas de defesa coletiva de tipo ideológico (DEJOURS, 1992) em atividades em que o risco de acidentes e sofrimento é muito intenso, tais como entre motoristas de caminhão (DELFINO, 2014) e motoboys (DRUMOND et al., 2007), sendo que muitas vezes as organizações se valem de tais defesas para intensificar seus processos de gestão e coerção, tais como se observou entre agentes penitenciários (BAGALHO, 2015) e modelos contemporâneos de gestão em empresas francesas (DEJOURS, 2007).

De todo modo, os homens e as mulheres, ao trabalharem, experimentam algo que é da ordem do enfrentamento, do confronto com o real, do inesperado, ou seja, daquilo que "se deixa conhecer pelo sujeito por sua resistência aos procedimentos, ao saber-fazer, à técnica, ao conhecimento, isto é, pelo fracasso imposto ao domínio sobre ele - o real" (DEJOURS, 2012a, p. 25). Ele coloca obstáculos para a realização do que quer que seja, fazendo que o trabalhar seja sempre uma experiência pática e afetiva, muitas vezes irritante, desesperadora e desagradável, que Dejours nomeia como sofrimento. Este se transforma em exigência de superação, colocando-se como desafio para o trabalhador e sendo ponto de partida para o desenvolvimento da inteligência no trabalho ou de adoecimento, no caso da impossibilidade de realizar tal transformação.

Entretanto, o real diz respeito não apenas à resistência do mundo material, mas também "do mundo social e, mais precisamente, das relações sociais na implantação da inteligência e da subjetividade" (DEJOURS, 2012a, p. 36). Trabalhar exige, desta forma, o enfrentamento, juntamente com os outros, de situações que escapam ao controle para realizar algo que seja considerado socialmente útil. Desta relação depende a saúde de quem trabalha, pois "as relações entre funcionamento psíquico e campo social não se articulam de maneira direta, mas são sempre mediatizadas pelo encontro com o real mobilizado pelo trabalho" (DEJOURS; GERNET, 2012, p. 63). Por mais que essa experiência possa ser muitas vezes desagradável, ela permite ao trabalhador ter a experiência do mundo e de si mesmo. Isso fica reduzido para aqueles que se afastam do trabalho regular por motivos diversos, como o adoecimento surgido ou agravado na própria atividade, o que não é sem consequências para esse trabalhador.

Considerando-se que o processo saúde-doença se relaciona intimamente à atividade mesma do trabalho, apresentaremos a seguir, algumas proposições de Dejours (1983) sobre o adoecimento relacionadas às rupturas involuntárias da atividade profissional.

\section{Adoecimento e rupturas involuntárias da atividade profissional}

Dentre as pesquisas realizadas junto aos trabalhadores que se afastaram do trabalho em decorrência da nocividade deste, em algumas delas (SILVA; OLIVEIRA; ZAMBRONI-DE-SOUZA，2011; ZAMBRONI-DE-

-SOUZA, 2006b) evidenciaram-se diversos problemas de saúde (psíquica e corporal), assim como problemas familiares e sociais. Além destes fatores, pode-se considerar que vivenciam enigmáticas contradições: alguns revelaram a vontade de se recolocar no mercado de emprego, mas não naquele meio em que estavam, percebido como fonte de seu mal; observam que por um lado há que tratar-se, mas desta forma seu salário se reduz, dados os gastos com medicamentos; afirmam experimentar a condição de estarem afastado da fonte de nocividade, mas tal condição os coloca em, uma situação social de improdutivos, o que afeta negativamente o tratamento. Assim se estabelece um ciclo vicioso que os afasta ainda mais da possibilidade de retomar a vitalidade e o emprego. Neste processo paradoxal, apesar de vivenciarem tanto sofrimento patógeno, buscam alternativas para sua situação e desejam reconstruir suas vidas.

Tal reconstrução, no entanto, mostra-se muito difícil, muitos não se recuperaram efetivamente do processo mórbido, de sua desestabilização, o que faz com que tragam consigo a ferida aberta de serem trabalhadores que, mesmo afastados temporariamente do emprego, "encostados pelo INSS", não foram capazes de se recuperar de fato. No caso de trabalhadores que retornaram e foram enquadrados na situação de "readaptados", pesquisas revelam o quanto os próprios colegas os renegam em uma dupla exclusão, caracterizada pela perseguição por parte da chefia e pelo abandono por parte dos colegas (SALIM, 2003; SANCHES et al., 2010; SILVA; OLIVEIRA; ZAMBRONI-DE-SOUZA, 2011; TOLDRÁ et al., 2010). Assim, como o trabalho se desdobra sempre em três universos - objetivo, social e subjetivo (DEJOURS; MOLINIER, 2004) - estes trabalhadores acabam por desenvolver problemas nessas três esferas.

Para (DEJOURS, 1983), dois grupos se distinguem diante dos afastamentos involuntários das atividades profissionais para as quais foram contratados: aqueles que realizam trabalho que requer anos de investimento em formação (como na indústria de processo contínuo); outros que exercem tarefas que não requerem tal qualificação, especialmente o trabalho de tipo repetitivo, taylorizado. Vamos colocá-los em análise.

No caso do primeiro grupo, a manutenção da estabilidade está relacionada aos seguintes fatores: a sublimação; a economia psicossomática; o passado psíquico; as relações afetivas atuais. Quanto à sublimação, na medida em que afastado do emprego e das atividades de trabalho que o compõe, o sujeito arrisca ver ruir uma construção cuidadosamente elaborada. Se antes as pulsões parciais se manifestavam, a partir do afastamento do emprego elas precisam buscar outros objetos, levando a grandes riscos de que se voltem perigosamente para o próprio sujeito e suas relações (DEJOURS, 1983).

No que diz respeito à economia psicossomática (conceito de base da teoria de Pierre Marty, fundador da Escola Psicossomática de Paris), para Dejours (1983, p. 1876) "a tarefa, sua organização, seu conteúdo, seus modos operatórios implicam exigências cognitivas, sensoriais e motoras, nas quais o sujeito engaja seus músculos, seus

Fractal, Rev. Psicol., v. 30 - n. 2, p. 103-111, 2018 
órgãos e seu sistema nervoso". Assim, uma ruptura involuntária do emprego não é sempre seguida de oportunidade de recolocar sua energia como era antes, requerendo que o trabalhador reorganize seus investimentos libidinais, o que nunca é simples de se obter, de modo a não trazer para si desestabilização no plano psicossomático.

Com relação ao passado psíquico, o trabalho pode ser capaz de oferecer satisfações substitutas aos desejos originários da infância. Assim, o exercício do trabalho abre a possibilidade para que haja transposições entre o teatro da infância e o teatro do trabalho, mesmo que entre eles se interponham "inevitavelmente diferenças ou desvios, que criam uma ambiguidade, um equívoco: $[. .$. a essa ambiguidade damos o nome de ressonância simbólica" (DEJOURS, 1996, p. 157), que permite conciliar o inconsciente e os objetivos da produção. Em sua falta, abrem-se as portas para as descompensações, capazes muitas vezes de terminarem com o afastamento do emprego. Isto porque na história de vida de cada um, parte das vivências de angústia infantil persiste até a vida adulta, podendo, no teatro do trabalho, encontrar uma nova oportunidade para descobrir encaminhamentos positivos, caso seja possível a ressonância simbólica. Neste caso, a descompensação apresenta-se como resultado de um jogo dinâmico da história passada com a atualidade vivida naquele meio de trabalho: ora permitindo que o sujeito possa reconhecer-se nesse teatro, ora o trabalho apresentando um conteúdo, muitas vezes cruel ou esvaziado de sentido, que o afaste das possibilidades de realizações (sempre parciais) de seus desejos. Afastar-se do emprego pode permitir a alguns a abertura a novas possibilidades de trabalho e emprego nos quais o teatro do trabalho ofereça resultados positivos para a identidade e a saúde. No entanto, como temos encontrado junto a trabalhadores adoecidos que buscam o Centro de Referência em Saúde do Trabalhador (CEREST), muitas vezes a intensidade de adoecimento e destruição de estruturas fisiológicas em decorrência de trabalhos grandemente nocivos é de tal monta que esses sujeitos têm pouquíssimas condições de retomarem um lugar no mercado de trabalho.

Por fim, quanto às relações afetivas atuais, a família participa do processo vivencial de sofrimento do trabalhador (DEJOURS, 2015a), de forma que o afastamento do emprego, em alguma medida, afetará todos os seus membros. Sobretudo as crianças e mulheres que, muitas vezes, em função de defesas ideológicas viris, são objeto de violência do homem, sistema defensivo cuja operacionalidade ajuda a mantê-lo em um quadro de normopatia (DEJOURS, 2007), permitindo assim que ele permaneça trabalhando em seu empregado. Em contrapartida, se frequentemente os trabalhadores usam o trabalho para fugir de problemas vividos nas relações afetivas no meio familiar, quando afastados são obrigados pelas circunstâncias a se defrontarem com tais relações, tendo que lidar com tais problemas, muitas vezes com descompensações psicossomáticas.

Por outro lado, para aqueles cujas atividades não exigem qualificação (particularmente o trabalho de tipo repetitivo) apresentam-se importantes diferenças em relação ao grupo anteriormente citado, que se manifes- tam sobretudo no campo "do desejo, da sublimação e da economia psicossomática” (DEJOURS, 1983, p. 1877). Cabe ressaltar que no Brasil, persiste muito trabalho repetitivo, parte dele responsável pelo afastamento de cem mil trabalhadores por ano (BRASIL, 2012). Segundo dados do Ministério da Saúde (BRASIL, 2001), os setores que apresentam maior incidência de trabalho repetitivo no Brasil são: bancário, metalúrgico, comércio, processamento de dados, têxtil, confecção, químico, plástico, serviços, telecomunicações, alimentação, vidreiro.

Uma primeira característica dos que se encontram neste quadro se coloca no plano do desejo, já que, em geral, essas pessoas não "escolheram estar na linha de montagem, na ferramenta mecânica ou vigiando a tela de visualização de uma indústria" (DEJOURS, 1983, p. 1877). No caso das tarefas prescritas segundo a racionalidade taylorista, elas se realizam frequentemente contra o desejo, já que força o bloqueio do funcionamento psíquico, levando a uma luta para se manter concentrado em sua realização, o que "exige do trabalhador um gasto de energia considerável” (DEJOURS, 1983, p. 1877), sendo muitas habilidades e competências pessoais exigidas aos trabalhadores. Desta forma, não há espaço para a sublimação e o trabalhador deve buscá-la fora do que efetua em seu emprego. Quanto à economia psicossomática, "a clivagem entre psique e soma e, ao limite, a paralisia mental que entrega o corpo sem defesa à organização do trabalho" (DEJOURS, 1983, p. 1877), favorece a depressão essencial (outro conceito-base da Psicossomática de Pierre Marty), que desemboca nas doenças somáticas. Para os que atuam neste contexto, o afastamento muitas vezes é vivido como um alívio, "uma verdadeira liberação. Liberação do funcionamento mental no início e um alívio em seguida" (DEJOURS, 1983, p. 1878). Não obstante, paradoxalmente, após um tempo de afastamento, muitas vezes emergem descompensações (mentais ou somáticas), pois sendo "brutalmente confrontados com as reaproximações afetivas, com familiares e amigos, sem poder utilizar-se do funcionamento mental paralisado ou lentificado, esses sujeitos estão de certo modo desarmados" (DEJOURS, 1983, p. 1878).

Os trabalhadores que estão, por decisão de perícia médica, afastados do emprego em função de adoecimento mantêm-se com vínculo empregatício enquanto estão licenciados pela Previdência Social (muitos perdem o emprego após o período legal de estabilidade). No entanto, por estarem involuntariamente afastados do emprego, vivenciam em parte situações semelhantes àqueles que estão no desemprego. Passam por altos níveis de desgaste mental, que se revela na forma de sentimento de "(des) socialização progressiva" (OLIVEIRA; MENDES, 2014, p. 391), impotência individual, sensação de carência de sentido da vida, distanciamento cultural, ausência de normas, autodistanciamento (SELIGMANN-SILVA, 2011). Além disso, tende a haver o aparecimento de depressão, de problemas com a autoestima, cognitivos e familiares (ÁLVARO, 1992), pois neles "a privação do trabalho introduz uma ruptura nos investimentos psíquicos e entra- 
va a dinâmica da sublimação, abrindo o caminho para as descompensações depressivas e somáticas” (DEJOURS; GERNET, 2012, p. 108).

\section{Perspectivas diante do afastamento}

Assim, considerando a dupla face do trabalho e o quadro paradoxal vivido por quem é afastado do emprego por adoecimento e licença médica, verifica-se por parte de trabalhadores um esforço de persistir na produção de sentido do trabalho que antes da licença experimentavam. Em alguns casos (DELFINO, 2014), verifica-se um esforço dos trabalhadores de elaboração de um projeto alternativo àquele emprego cuja situação de trabalho mostrou-se nocivo. Em geral por meio da busca de alguma outra modalidade de trabalho, mesmo fora do estatuto de emprego, que pudesse tornar viável sua sustentação financeira, a médio e longo prazos (especialmente na velhice). Nesse caso, a radicalidade da aposentadoria por invalidez nem sempre é considerada uma opção indesejável, pois para alguns ela ofereceria uma base financeira para colaborar no encaminhamento de outros projetos. Também se verifica que alguns se lançam em outras estratégias, como por exemplo a retomada de estudos, a mudança de residência, a manutenção do mesmo tipo de trabalho, mas fora do estatuto do emprego, na "informalidade". Importa ressaltar que o apoio da rede familiar e de outras redes de apoio societário, como programas de reabilitação profissional, o acesso a cursos de formação/requalificação, de complementação da escolarização, o acesso a outras atividades profissionais, são fundamentais para que tal afastamento possa ser vivido de maneira mais positiva, viabilizando tanto novos projetos profissionais e familiares quanto novas perspectivas profissionais.

No caso da rede familiar, malgrado muitos trabalhadores que vivem a situação aqui em foco experimentem diversas formas de conflito, outros reconstroem essas relações ressignificando positivamente outras atividades sociais de trabalho, tais como o cuidado dos filhos, de eventuais outros membros vulneráveis, do trabalho doméstico em seu amplo conjunto (DELFINO, 2014).

Verifica-se, portanto, que a relação entre trabalho, subjetividade e saúde-doença, envolvendo o sujeito e seu coletivo, quando não possibilitado por meio das atividades profissionais desenvolvidas em seu emprego, pode ser parcialmente reconstruída em atividades de trabalho doméstico, sem que as dinâmicas psíquicas sejam totalmente desestruturadas, ao ponto de descompensar os trabalhadores. Ressaltada a importância do apoio da rede familiar nesse processo, diríamos que também seriam fundamentais para tais processos políticas públicas efetivamente existentes, viabilizando ao menos espaços de fala, profissionalmente estruturados e operados. Embora oficialmente o INSS ofereça o serviço de Reabilitação Profissional "que tem o objetivo de oferecer aos segurados incapacitados para o trabalho, por motivo de doença ou acidente, os meios de reeducação ou readaptação profissional para o seu retorno ao mercado de trabalho"
(BRASIL, 2013), há imensas dificuldades para o trabalhador que se utiliza deste serviço na retomada do trabalho após o afastamento (DELFINO, 2014).

\section{Considerações finais}

A problemática que envolve o afastamento do trabalho em função de adoecimento não é recente, como mostram os textos que contam a trajetória da história do campo da Saúde do Trabalhador (LACAZ, 2007; MENDES; DIAS, 1991), assim como aqueles dos fundadores da Psicopatologia do Trabalho (LE GUILLANT, 1984; SIVADON, 1952). No entanto, permanece como um problema que ainda nos instiga tanto do ponto de vista acadêmico quanto social. Pode-se evidenciar a permanência da problemática em textos produzidos fora da Psicodinâmica do Trabalho, como o de Lacaz (2016), que aponta que os trabalhadores continuam até mesmo a morrer apesar de décadas de ações em Saúde do Trabalhador, ou mesmo pelos documentos oficiais que mostram os problemas que levam a afastamento do trabalho por doença (BRASIL, 2017b). Também dentro da Psicodinâmica do Trabalho tal questão permanece central e, pior, com os recentes modelos de gestão produzidos em consonância com o neoliberalismo, tal quadro tende a se agravar (DEJOURS, 2012b; 2015b; SANTOS, 2017). Esta situação vem chamando a atenção não apenas entre os empregados, mas até mesmo no meio empresarial, em especial entre os pequenos e médios empresários (OLIVEIRA-DE-SOUTO, 2017; THURIK et al., 2016).

Diante deste quadro, diversas questões merecem reflexões, que apontamos a seguir, mas que pelos limites deste artigo, serão desenvolvidas com mais detalhes em outro momento. Um desses aspectos diz respeito à chamada reabilitação profissional, que acaba muitas vezes por não permitir que o trabalhador volte a trabalhar em uma função que tenha relação com sua capacidade e seus desejos (DELFINO, 2014), diminuindo a possibilidade de reconstrução de sua saúde pela ressonância simbólica (DEJOURS, 1996). Em diversas situações, os trabalhadores ao voltar do processo de readaptação são colocados em situação de exclusão, de assédio, seja pela gerência (SILVA; OLIVEIRA; ZAMBRONI-DE-SOUZA, 2011), seja pelos próprios colegas (BRITO; ATHAYDE, 2003), somada ao fato que o poder público negligencia a fiscalização destes processos (RAMOS JÚNIOR, 2016).

Como este artigo visa analisar, a partir da abordagem da PDT, a dinâmica psíquica de trabalhadores afastados do emprego por doença surgida ou agravada no próprio trabalho, outra questão se coloca no que diz respeito ao método. A PDT utiliza como ferramenta privilegiada de investigação a enquete, conforme a descrição de Dejours (1988) apresentada pela primeira vez no Seminário Interdisciplinar de Psicopatologia do Trabalho organizado pela AOCIP. Tal proposta, cujo texto está disponível no Brasil em duas publicações (DEJOURS, 1992; DEJOURS, 2004c), permanece como texto central para essa abordagem.

Para Dejours (2004c, p. 105), a enquete "deve partir de uma demanda". No caso específico dos trabalhadores que em geral buscam os Centros de Referência em Saú- 
de do Trabalhador (CEREST) pelo Brasil, a demanda se configura de maneira individual por trabalhadores advindos de diversos meios laborais em busca de apoio para seus problemas de saúde e/ou previdenciários. Não se trata, portanto, de trabalhadores que compõem o mesmo grupo profissional nem que trabalhavam necessariamente em um mesmo meio, de tal forma que dificilmente surgiria uma demanda coletiva deles. Seguindo o que aponta Dejours (1992, p. 27), este grupo "não se caracteriza pela participação comum em uma mesma tarefa [...]. Ao contrário, o que o une é mais o não trabalho". Pode-se propor que a situação de afastamento de emprego gere temas em comum, que podem ser objetos de formação de grupos ad hoc no próprio CEREST. Os participantes, assim, formam "um 'grupo homogêneo' [...] por categorias subjetivas, ou seja, são a demanda e seu conteúdo que definem o coletivo estudado" (DEJOURS, 2004c, p. 114).

Trata-se, portanto, de uma tentativa, cujo primeiro autor deste artigo está buscando realizar no CEREST da cidade onde vive, ainda sem resultados, já que os próprios funcionários do CEREST relatam que esses trabalhadores têm imensas dificuldades de se locomover: seja pela própria doença e inadequação dos transportes públicos no Brasil (ônibus altíssimos que são feitos sobre chassis de caminhões, que impõem imensas dificuldades para pessoas com limitações de movimentos), seja pela carência de recursos financeiros para custear tais deslocamentos. Apesar dessas dificuldades iniciais, caso essa experiência se mostre exitosa, se conseguirmos superar os obstáculos ora apresentados, na primeira etapa, o trabalho dos pesquisadores profissionais será permitir que a solicitação trazida individualmente seja reelaborada e reformulada em um "trabalho de demanda" (DEJOURS, 2004a, p. 85), para que se transforme em uma demanda coletiva de pessoas que não obstante sejam provenientes de meios de trabalhos diferentes, se encontram em uma situação semelhante, podendo assim tentar formar as bases da cooperação, bases que provavelmente faltaram a eles durante a atividade de trabalho, o que favoreceu o aparecimento e/ou o agravamento da doença.

\section{Referências}

ÁlVARO, J. L. Desempleo y bienestar psicológico. Madrid: Siglo XXI de España, 1992.

BAGALHO, J. O. Sofrimento e prazer: uma análise psicodinâmica do trabalho prisional. 2015. Dissertação (Mestrado em Psicologia)- Universidade Federal do Espírito Santo, Vitória, 2015. Disponível em: http://repositorio.ufes.br/ handle/10/3116. Acesso em: 11 dez. 2017.

BILLIARD, I. Santé mentale et travail: l'emergence de la psychopathologie du travail. Paris: La Dispute/SNEDIT, 2001.

BRASIL. Presidência da República. Casa Civil. Subchefia para Assuntos Jurídicos. Decreto-Lei $n^{\circ} 5.452$, de $1^{\circ}$ de maio de 1943. Aprova a Consolidação das Leis do Trabalho. Disponível em: http://www.planalto.gov.br/ccivil 03/decreto-lei/Del5452. htm. Acesso em: 11 dez. 2017.

Fractal, Rev. Psicol., v. 30 - n. 2, p. 103-111, 2018
BRASIL. Presidência da República. Casa Civil. Subchefia para Assuntos Jurídicos. Lei $n^{\circ} 8.213$, de 24 de julho de 1991. Dispõe sobre os Planos de Benefícios da Previdência Social e dá outras providências. Disponível em: http://www.planalto. gov.br/ccivil_03/leis/18213cons.htm. Acesso em: 11 dez. 2017.

BRASIL. Ministério da Saúde. Secretaria de Políticas em Saúde. Lesões por esforços repetitivos (LER). Distúrbios osteomusculares relacionados ao trabalho (DORT). 2001. Disponível em: http://bvsms.saude.gov.br/bvs/publicacoes/ ler_dort.pdf. Acesso em: 11 dez. 2017.

BRASIL. Portal Brasil. Lesão por esforço repetitivo (LER). 2012. Disponível em: http://www.brasil.gov.br/saude/2012/04/ lesao-por-esforco-repetitivo-ler. Acesso em: 6 fev. 2016.

BRASIL. Ministério da Previdência Social. Reabilitação profissional. 2013. Disponível em: http://www.previdencia. gov.br/servicos-ao-cidadao/informacoes-gerais/reabilitacaoprofissional/. Acesso em: $11 \mathrm{dez} .2017$.

BRASIL. Ministério da Fazenda. Secretaria de Previdência, Empresa de Tecnologia e Informações da Previdência. Anuário Estatístico da Previdência Social, v. 24. 2015. Disponível em: http://www.previdencia.gov.br/wp-content/uploads/2015/08/ AEPS-2015-FINAL.pdf. Acesso em: 3 abr. 2017.

BRASIL. Presidência da República. Casa Civil. Subchefia para Assuntos Jurídicos. Lei 13.467, de 13 de julho de 2017. Altera a Consolidação das Leis do Trabalho (CLT), aprovada pelo Decreto-Lei $n^{\circ} 5.452$, de $1^{\circ}$ de maio de 1943 , e as Leis $n^{\text {os }}$ 6.019 , de 3 de janeiro de $1974,8.036$, de 11 de maio de 1990 , e 8.212 , de 24 de julho de 1991, a fim de adequar a legislação às novas relações de trabalho. 2017a. Disponível em: http://www. planalto.gov.br/ccivil 03/ ato2015-2018/2017/lei/L13467. htm. Acesso em: 11 dez. 2017.

BRASIL. Portal Brasil. Dor nas costas é a maior causa de afastamento do trabalho. 2017b. Disponível em: http://www. brasil.gov.br/economia-e-emprego/2017/04/dor-nas-costas-ea-maior-causa-de-afastamento-do-trabalho. Acesso em: 24 mai. 2017

BRITO, J.; ATHAYDE, M. Trabalho, educação e saúde: o ponto de vista enigmático da atividade. Trabalho, Educação e Saúde, Rio de Janeiro, v. 1, n. 2, p. 239-265, set. 2003. Cross ${ }^{\text {Ref. }}$

BRITO, J.; ATHAYDE, M.; NEVES, M. Y. (Ed.). Cadernos de textos. Programa de Formação em Saúde, Gênero e Trabalho nas Escolas. João Pessoa: UFPB, 2003.

BRITO, J. et al. (Ed). Cadernos de relatos de experiências. Programa de Formação em Saúde, Gênero e Trabalho nas Escolas. João Pessoa: UFPB, 2003.

CAVALCANTI, T.; ZAMBRONI-DE-SOUZA, P. C.; UCHÔADE-MEDEIROS, N. M. Programa de Saúde do Trabalhador do Hospital Universitário Lauro Wanderley (PROSAT/HULW/ UFPB). João Pessoa: UFPB 2013.

DEJOURS, C. Travail,usure mentale: essay de psychopathologie du travail. Paris: Bayard, 1980.

DEJOURS, C. Réactions psychopathologiques aux ruptures involontaires d'activité professionnelle (retraite, licenciement, maladie, reclassement). Psychologie médicale, v. 15, n. 11, p. 1875-1880, 1983.

DEJOURS, C. (Ed). Plaisir et souffrance dans le travail. Paris: AOCIPed, 1988.

DEJOURS , C. A loucura do trabalho: estudo de psicopatologia do trabalho. São Paulo: Cortez/Oboré, 1992. 
DEJOURS, C. Uma nova visão do sofrimento nas organizações. In: CHANLAT, J.-F. (Ed.). O individuo na organização. São Paulo: Atlas, 1996. p. 150-173.

DEJOURS , C. O fator humano. Rio de Janeiro: FGV, 1999.

DEJOURS, C. Addendum: da psicopatologia à psicodinâmica do trabalho. In: LANCMAN, S.; SZNELWAR, L. I. (Ed.). Christophe Dejours: da psicopatologia à psicodinâmica do trabalho. Rio de Janeiro: Fiocruz, 2004a. p. 47-104.

DEJOURS, C. As relações domésticas: entre amor e dominação. In: LANCMAN, S.; SZNELWAR, L. I. (Ed.). Christophe Dejours: da psicopatologia à psicodinâmica do trabalho. Rio de Janeiro: Fiocruz, 2004b. p. 317-336.

DEJOURS, C. A metodologia em psicopatologia do trabalho. In: LANCMAN, S.; SNELWAR, L. I. (Ed.). Christophe Dejours: da psicopatologia à psicodinâmica do trabalho. Rio de Janeiro: Fiocruz, 2004c. p. 105-126.

DEJOURS, C. A banalização da injustiça social. Rio de Janeiro: FGV, 2007.

DEJOURS, C. Entre o desespero e a esperança: como reencantar o trabalho. Revista CULT, São Paulo, v. 139, n. 12, p. 49-53, 2009. Disponível em: https://revistacult.uol.com.br/ home/reencantar-o-trabalho/. Acesso em: 24 maio 2017.

DEJOURS, C. La panne: repenser le travail et changer la vie. Montrouge: Bayard, 2012a.

DEJOURS, C. Souffrance au travail, enjeux et politique de santé publique. In: TÉLÉCOM-ORANGE, C. F.; DEJOURS, C. (Ed.). Souffrance au travail: regards croisés sur des cas contrets - comprendre, prévenir, agir. Lyon: Chronique Sociale, 2012b. p. 13-26.

DEJOURS, C. Trabalho vivo. Brasília: Paralelo 15, 2012c.

DEJOURS, C. A sublimação, entre sofrimento e prazer no trabalho. Revista Portuguesa de Psicanálise, v. 33, n. 2, p. 9-28, 2013. Disponível em: http://docplayer.com.br/24920304A-sublimacao-entre-sofrimento-e-prazer-no-trabalho-1.html. Acesso em: 23 maio 2017.

DEJOURS, C. Travail, usurementale: essay de psychopathologie du travail. Nouvelle édition augmentée. Montrouge: Bayard, 2015a.

DEJOURS, C. Le choix, souffrir au travail n'est pas une fatalité. Montrouge: Bayard, 2015b.

DEJOURS, C.; GERNET, I. Psychopathologie du travail. Issyles-Moulineaux: Paris: Elsevier Masson, 2012.

DEJOURS, C.; MOLINIER, P. O trabalho como enigma. In: LANCMAN, S.; SNELWAR, L. I. (Ed.). Christophe Dejours: da psicopatologia à psicodinâmica do trabalho. Rio de Janeiro: Fiocruz, 2004. p. 127-139.

DELFINO, L. G. Da boleia à previdência social: sentidos do afastamento do trabalho para caminhoneiros de rota longa. 2014. Dissertação (Mestrado em Psicologia)-Universidade Federal do Espírito Santo, Vitória, 2014. Disponível em: http:/ repositorio.ufes.br/handle/10/3105. Acesso em: 24 maio 2017.

DRUMOND, T. et al. Estratégias de defesa em constituição: entre a virilidade e a solidariedade. In: ZANOTELLI, C.; RAIZER, E. C. (Ed.). Violência e contemporaneidade: dimensões das pesquisas e impactos sociais. Vitória: Grafita, 2007. p. 189-205.
GUÉRIN, F. et al. Compreender o trabalho para transformá-lo: a prática da ergonomia. São Paulo: Edgar Blücher, 2012.

HIRATA, H.; KERGOAT, D. Novas configurações da divisão sexual do trabalho. Cadernos de Pesquisa, São Paulo, v. 37, n. 132, p. 595-609, set./dez. 2007. Cross ${ }^{\text {Ref. }}$

INTERNATIONAL LABOR ORGANIZATION. The prevention of occupational diseases. Geneva: ILO, 2013.

LACAZ, F. A. C. O campo Saúde do Trabalhador: resgatando conhecimentos e práticas sobre as relações trabalho-saúde. Cad. Saúde Pública, v. 23, n. 4, p. 757-766, 2007. Cross ${ }^{\text {Ref. }}$

LACAZ, F. A. C. Continuam a adoecer e morrer os trabalhadores: as relações, entraves e desafios para o campo Saúde do Trabalhador. Revista Brasileira de Saúde Ocupacional, v. 41, n. 13, p. 1-11, 2016. Cross ${ }^{\text {Ref. }}$

LE GUILLANT, L. (Ed). Quelle Psychiatrie pour notre temps? Travaux et écrits de Louis Le Guillant. Toulouse: Erèsed, 1984.

MENDES, R.; DIAS, E. C. Da medicina do trabalho à saúde do trabalhador. Revista de Saúde Pública, v. 25, n. 5, p. 341-349, 1991. Cross ${ }^{\text {Ref. }}$

MODZELESKI, A. Brasil fecha 1,5 mi de vagas com carteira em 2015, pior resultado desde 92. Uol Economia, Brasília, 21 jan. 2016. Disponível em: https://economia.uol.com.br/ empregos-e-carreiras/noticias/redacao/2016/01/21/brasilfecha-1542371-vagas-com-carteira-assinada-em-2015.htm. Acesso em: 21 maio 2017.

OLIVEIRA-DE-SOUTO, C. H. A relação sofrimento/ prazer dos empresários do setor de seguros no exercício da sua atividade profissional. 2017. Dissertação (Mestrado em Psicologia)- Universidade Federal da Paraíba, João Pessoa, 2017. Disponível em: http://tede.biblioteca.ufpb.br:8080/ handle/tede/9125. Acesso em: 24 maio 2017.

OLIVEIRA, J. L.; MENDES, A. M. Sofrimento psíquico e estratégias defensivas utilizadas por desempregados: contribuições da psicodinâmica do trabalho. Temas em Psicologia, v. 22, n. 2, p. 389-399, 2014. Cross ${ }^{\text {Ref. }}$

PEZÉ, M. Ils ne mouraient pas tous mais tous étaient frappés. Paris: Pearson Éducation France, 2008.

RAMOS JÚNIOR, W. Reabilitação profissional realizada pelo INSS e a volta do trabalhador com baixa instrução para o mercado de trabalho. SaberaLei, São Paulo, 19 mar. 2016. Disponível em: http://saberalei.com.br/reabilitacaoprofissional-realizada-pelo-inss/. Acesso em: 24 mai. 2017.

SALIM, C. A. Doenças do trabalho: exclusão, segregação e relações de gênero. São Paulo em Perspectiva, v. 17, n. 1, p. 11-24, jan./mar. 2003. Cross ${ }^{\text {Ref. }}$

SANCHES, E. N. et al. Organização do trabalho, sintomatologia dolorosa e significado de ser portador de LER/DORT. Psicol. Argum., v. 28, n. 63, p. 313-324, 2010. Disponível em: http://www2.pucpr.br/reol/pb/index.php/ pa?dd1 $=3933 \& d d 99=$ view $\& d d 98=$ bb. Acesso em: 23 maio 2017.

SANTOS, J. O. A. Compreendendo o papel da cooperação nos casos de afastamento do trabalho por motivo de doença. 2017. Dissertação (Mestrado)- Universidade Federal da Paraíba, João Pessoa, 2017.

SCHWEITZER, S. Les femmes ont toujours travaillé: une histoire du travail des femmes aux XIXe et XXe siècles. Paris: Odile Jacob, 2002. 
SELIGMANN-SILVA, E. Trabalho e desgaste mental: o direito de ser dono de si mesmo. São Paulo: Cortez, 2011.

SILVA, E. F.; OLIVEIRA, K. K.; ZAMBRONI-DE-SOUZA, P. C. Saúde mental do trabalhador: o assédio moral praticado contra trabalhadores com LER/DORT. Revista Brasileira de Saúde Ocupacional, São Paulo, v. 36, n. 123, p. 56-70, jan./ jun. 2011. Cross ${ }^{\text {Ref }}$

SIVADON, P. Psycho-pathologie du Travail. L'Evolution Psychiatrique, v. 3, p. 441-444, 1952.

THURIK, R. et al. ADHD Symptoms and Entrepreneurial Orientation of Small Firm Owners. Applied Psychology: an international review, v. 65, n. 3, p. 568-586, jul. 2016. Cross ${ }^{\text {Ref. }}$

TOLDRÁ, R. C. et al. Facilitadores e barreiras para o retorno ao trabalho: a experiência de trabalhadores atendidos em um Centro de Referência em Saúde do Trabalhador - SP, Brasil. Revista Brasileira de Saúde Ocupacional, v. 35, n. 121, p. 1022, jan./jun. 2010. Cross ${ }^{\text {Ref. }}$

VIDAL, D. Les bonnes de Rio: emploi domestique et société démocratique au Brésil. Villeneuve d'Ascq: Presses universitaires du Septentrion, 2007.

ZAMBRONI-DE-SOUZA, P. C. O trabalho como possivel: o caso das pessoas com "transtornos mentais graves". 2006. Tese (Doutorado em Psicologia)-Universidade do Estado do Rio de Janeiro, Rio de Janeiro, 2006a.

ZAMBRONI-DE-SOUZA, P. C. Trabalhando com saúde: trabalho e transtornos mentais graves. Psicologia em Estudo, Maringá, v. 11, n. 1, p. 175-183, jan./abr. 2006b. Cross ${ }^{\text {Ref. }}$

ZAMBRONI-DE-SOUZA, P. C.; ATHAYDE, M. A. A contribuição da abordagem clínica de Louis Le Guillant para o desenvolvimento da Psicologia do Trabalho. Estudos e Pesquisas em Psicologia, v. 6, n. 1, p. 6-19, jun. 2006. Disponível em: http://pepsic.bvsalud.org/scielo. php?script=sci_arttext\&pid=S1808-42812006000100002\&lng $=$ pt\&nrm=iso\&tlng=pt. Acesso em: 24 maio 2017.

ZAMBRONI-DE-SOUZA, P. C. et al. O pioneirismo de Louis Le Guillant na reforma psiquiátrica e psicoterapia institucional na França: a importância do trabalho dos pacientes para a abertura dos hospícios. Estudos e Pesquisas em Psicologia, Rio de Janeiro, v. 9, n. 3, p. 612-631, jan./dez. 2009. Disponível em: $\quad$ http://pepsic.bvsalud.org/scielo.php?script=sci arttext\&pid=S1808-42812009000300005. Acesso em: 24 maio 2017.

Recebido em: 1 de junho de 2017 Aceito em: 15 de dezembro de 2017 